\title{
Verification of Wegelin's design criteria for horizontal flow roughing filters (HRFs) with alternative filter material
}

\author{
GM Ochieng and FAO Otieno* \\ Faculty of Engineering, Tshwane University of Technology (Pretoria), Private Bag X680, Pretoria 0001 Republic of South Africa
}

\begin{abstract}
Wegelin's design criteria founded on the " $1 / 3-2 / 3$ " filter theory are still to date the most comprehensive models applied in design of roughing filters. This study aimed at verifying these criteria based on gravel as a filter medium and two other possible alternative filter media, namely broken burnt bricks and charcoal maize cobs. Gravel was used as a control medium since it is one of the most commonly used roughing filter media and also because it was used in developing these criteria. The per cent reduction in raw water suspended solids (SS) concentration was compared against the expected model prediction. SS was used as a parameter of choice since the " $1 / 3-2 / 3$ " filter theory is based on SS reduction. A pilot plant study was undertaken to meet this objective. The pilot plant was monitored for a continuous 85 days from commissioning till the end of the project. Results showed that in general, filters filled with charcoal maize cobs and broken burnt bricks were off model prediction by $13 \%$ compared to gravel's $15 \%$. The performances also varied in both low- and high-peak periods. It is concluded that the Wegelin's design criteria should be used as a guideline step followed by actual field and laboratory tests to establish the actual filter design parameters in line with the filter media in use and the quality of the raw water to be treated.
\end{abstract}

Keywords: Wegelin's design criteria, horizontal flow roughing filtration

\section{Introduction}

Hydraulic design of water treatment/filtration plants is mostly based on the various filtration theories that subscribe to the contemporary accepted scientific paradigms. Many of these are developed in laboratories and field studies at different locations with different conditions from where the actual implementation takes place. More often, the extension or implementation of such scientific theories or appropriate technologies is done in a blanket manner. In some instances, this process has led to failure in replication of the expected performance of the respective technology or scientific theory. For instance, Michele and Johannes (2004) in their study to investigate the possible reasons for excessive media losses during backwashing in a number of water treatment plants in South Africa, highlighted certain flaws in the common practices with respect to design of water filtration plants. In this study, they found compelling evidence that design procedures based on oven-dried laboratory samples underestimate the expansion of the bed after it has been in service for a number of months or years. In this regard, they further suggested the application of correction factors in the Dharmarajah and Cleasby model (the most comprehensive to date) to allow for more expansion during eventual plant operation. Given that the structural design of water treatment/filtration plants largely depend on the ensuing hydraulic design, it is thus prudent on the designers and engineers in this field to undertake some validation exercise on the theories (models) before full-scale implementation is carried out. This is important to avoid costly and wasteful utilisation of the available resources.

The application of appropriate technology in the provision of potable drinking water to the rural community needs a proper

* To whom all correspondence should be addressed.

前 +2712 3185120; fax: +27123185568 ;

e-mail: otienofao@tut.ac.za

Received 5 July 2004; accepted in revised form 10 October 2005. examination of the underlying principles given the crucial need for its success and sustainability. In most instances though, this exercise is undertaken through duplication of success stories from other regions or in cases where pilot-plant studies are undertaken, insufficient time is given for the development of adequate features and parameters for the adoption of such projects needs.

Use of appropriate technologies such as multistage filtration (MSF), a combination of pretreatment system (e.g. roughing filters) and slow sand filtration (SSF) in provision of potable drinking water to the rural community is being encouraged (WHO, 2004; Ochieng' et al., 2004). This is so given the success shown by such systems over the years in many countries, e.g. Rwanda (Clarke et al., 2004), Ethiopia (Mesfin, 1999), Sri Lanka (Jayalath and Padmasiri, 1996) among many others.

The horizontal flow roughing filter (HRF) is commonly applied with SSF especially in the developing countries (e.g. Jayalath and Padmasiri, 1996; Mesfin, 1999; Torabian and Fazeli, 2004). To date, the most comprehensive model applied in HRF design is based on Wegelin design criteria founded on the “1/3 - 2/3" filter theory (Wegelin, 1986; 1996).

\section{The " $1 / 3-2 / 3$ " filter theory}

The " $1 / 3-2 / 3$ " filter theory as described by Wegelin (1986, 1996) is a conceptual filter theory. The literature and principles behind the theory are quite elaborate and it would therefore suffice only to mention the salient points to enhance the reader's understanding of the proceedings hereafter (for in-depth documentation on this theory, refer to Wegelin, 1986; 1996 and the references therein).

By logic and experience, a particle in water can bypass a gravel grain (filter-medium grain) either on the left or on the right or settle on its surface. Hence the chance to fall on the grain (success of removal) is $1 / 3$ and $2 / 3$ chance of failure of removal. However, the process continues as there is a second, third and 
many other grains to settle on. Thus if a given quantity of settleable particles enter the filter, the quantity would be reduced in successive layers as per this probability along the flow path. This theory has been used to formulate models, which give a simple elucidation of the removal kinetics of the roughing filters and hence are further used to describe the filter efficiencies in HRF design.

The mathematical description of this theory would show that solids separation by filtration can be described by an exponential equation. Based on Fick's law and other established filter theories, the filter efficiency can be expressed by the filter coefficient $\lambda$ or

$$
\frac{d c}{d x}=-\lambda c
$$

where:

$$
\begin{aligned}
c= & \text { solids concentration } \\
\boldsymbol{x}= & \text { filter depth } \\
\lambda= & \text { coefficient of proportionality also known as filter } \\
& \text { coefficient }
\end{aligned}
$$

Equation (1) states that the removal of suspended particles is proportional to the concentration of the particles present in water.

Assuming the total filter length as a multi-tore reactor consisting of a series of smaller filter cells, the performance of an HRF can be calculated on the basis of the filter cell test results. Neglecting straining mechanisms and further assuming surface chemical conditions to be constant, the total suspended solids (SS) concentration after an element $\Delta \boldsymbol{x}$ can be estimated by the following expression:

$$
c_{\text {out }}=\sum c_{i(i n)} e^{-\lambda_{i} \Delta x}
$$

where:

$$
\begin{aligned}
& \lambda_{i}=\text { filter coefficient for each filter cell } \\
& \Delta x=\text { the length of the experimental filter cell } \\
& c_{i}=\text { concentration of particles of size } \boldsymbol{d}_{p i}
\end{aligned}
$$

Equation (2) shows that in knowing the inlet SS concentration, the filter coefficient, and the filter depth (length), we could readily predict the outlet SS concentration and consequently predict the filter performance efficiency. This aids in filter design

According to Wegelin $(1986 ; 1996)$, the effluent quality for an $n$ number of compartments is given by the following expression:

$$
C_{e}=C_{0} * E_{1} * E_{2} * \ldots . . * E_{n}
$$

where:

$C_{0}$ is the concentration in the HRF influent

$C_{e}$ is the concentration in the HRF effluent

$E_{i}$ are the filtration "efficiencies" for $i=1,2 \ldots \mathrm{n}$

compartments respectively.

The basic expression for the above relationship is:

$$
C_{e}=C_{0} e^{-\lambda L}
$$

where:

$\lambda$ is the coefficient of filtration (also known as filter coefficient)

$\mathrm{L}$ is the length of filter.

The filter efficiency is given by:

$$
E=\frac{C_{e}}{C_{0}}=e^{-\lambda L}
$$

$$
\therefore C_{e}=C_{0} * E
$$

The values of $E_{i}(i=1,2 \ldots \mathrm{n})$ are obtained either from tables or graphical nomograms as developed by Wegelin (see mentioned reference for further details). Using Eq. (6) and the total $E$-value for the whole filter, Table 2 was generated for predicted HRF effluent, $\boldsymbol{C}_{e}$ (expected model output) for every recorded field raw water SS, $\boldsymbol{C}_{\boldsymbol{0}}$.

\section{Objectives}

A general objective of the study was to evaluate the performance of possible alternative roughing filter media, using the Wegelin's design criteria for HRF based on the " $1 / 3-2 / 3$ " filter theory. The reference criterion would be the reduction of SS loads in the raw water. Specific objectives were to verify Wegelin's design criteria for HRF with respect to the study area raw water conditions as this would be unique in characteristics compared to the one used to develop the design criteria (Wegelin used kaolin clay to make up the SS load). The study also endeavoured to determine the suitability of the extension of this criterion to filter material other than gravel. In this case, alternative locally available filter material, i.e. charcoal maize cob and broken burnt brick were tested.

\section{Experimental}

\section{General}

To investigate the research objectives, a pilot plant was built at Moi University water treatment works in the year 2000. The location of the pilot plant at the campus was for convenience and logistic reasons. The plant could, however, have been sited anywhere else.

Three filter materials were tested in this study. These were charcoal maize cob, broken burnt brick and gravel. Gravel was used as a control material since Wegelin's criteria were based on experiments carried out using gravel as the filter medium. To enable a comparative study, three HRF units were constructed for each filter material. The three HRF materials were placed each in their own filter units and then simultaneously tested using the same raw water source.

The inlet SS concentration (raw water - same for all the units) and outlet SS concentrations were analysed using the gravimetric method following standard procedures as laid out in Standard Methods (1995).

Sampling was done three times a week for a period of 85 days. The sampling points were the inlets and outlets of the HRF units. Analysis of the samples was done immediately after sampling in the university's Public Health Laboratory. The experimentation was organised such that both the low flow (dry season) and high flow (wet season) periods were covered during this period.

\section{Pilot plant unit (HRF)}

The design and sizing of the pilot plant HRFs were guided by the Wegelin design criteria (Wegelin, 1986) based on the preliminary raw water quality data obtained prior to the commencement of the full pilot plant study. Tests done on the raw water feeding Moi University Water Treatment Works showed that the SS concentrations ranged between 60 to $200 \mathrm{mg} / \ell$. According to the Wegelin's design guidelines, this falls in the medium range (100 to $300 \mathrm{mg} / \ell$ ) for which filtration rates of 0.75 to $1 \mathrm{~m} / \mathrm{h}$ are 


\begin{tabular}{|c|c|c|c|c|}
\hline \multirow{2}{*}{\multicolumn{2}{|c|}{$\begin{array}{c}\text { Figure } 1 \\
\text { Schematic } \\
\text { layout and } \\
\text { design } \\
\text { details of } \\
\text { pilot HRF }\end{array}$}} & Inlet & \multicolumn{2}{|c|}{ al distribution chamber } \\
\hline & & Underdrains & \multicolumn{2}{|c|}{$\mathrm{dg}=15 \mathrm{~mm}$} \\
\hline \multicolumn{5}{|c|}{$\begin{array}{l}\text { commended. In this study, a constant filtration rate of } 0.75 \\
\text { as chosen for the HRF units. Using the Wegelin's nomogr } \\
\text { d the design guidelines, the following } E \text { values (Table } 1 \text { ) } \\
\text { tained for use in the design of the HRF units. }\end{array}$} \\
\hline \multicolumn{5}{|c|}{$\begin{array}{c}\text { TABLE 1 } \\
\begin{array}{c}E \text {-values for the various compartments and the } \\
\text { total } E \text {-value for the whole filter }\end{array}\end{array}$} \\
\hline $\begin{array}{l}\text { Effec- } \\
\text { tive } \\
\text { size } d_{g} \\
(\mathrm{~mm})\end{array}$ & $\begin{array}{l}\text { Filtra- } \\
\text { tion } \\
\text { rate } V_{f} \\
(\mathrm{~m} / \mathrm{h})\end{array}$ & $\begin{array}{l}\text { Compart- } \\
\text { ment filter } \\
\text { length } L_{f} \\
(\mathrm{~m})\end{array}$ & $\begin{array}{c}E_{i} \text {-value } \\
(\%)\end{array}$ & $\begin{array}{l}\text { Total } E \\
\text { - value } \\
\text { (dec) }\end{array}$ \\
\hline 5 & 0.75 & 1 & $E_{1}=28.3$ & \multirow{3}{*}{0.028} \\
\hline 10 & 0.75 & 2 & $E_{2}=25.7$ & \\
\hline 15 & 0.75 & 2 & $\mathrm{E}_{3}=39.0$ & \\
\hline
\end{tabular}

where $d_{g}$ is the effective size of the filter material in each compartment.

In this case, three compartments were used for each filter unit. The filter was divided into three parts:

- The inlet structure

- The outlet structure

- The filter bed.

The inlet and outlet structures were flow-control installations required to maintain a certain water level and flow along the filter as well as to establish an even flow distribution along and across the filter. The filter bed was composed of three filter medium packs of different sizes $\left(\mathrm{d}_{\mathrm{g}}\right)$.

The filter medium was placed in separate compartments starting with the coarsest to the finest, in the direction of flow and operated in series. The first compartment was filled with filter material of effective size $15 \mathrm{~mm}$ followed by $10 \mathrm{~mm}$ in the second compartment and $5 \mathrm{~mm}$ in the last compartment. Perforated wall segments to avoid mixing during cleaning separated each fraction. The filter bed was provided with under-drain systems to enable hydraulic sludge extraction "flushing" to be carried out after a certain running period when the resistance in the bed was observed to be increasing. This was checked via a rise in the water level in the equal distribution chamber (see Fig. 1). Since the rate of rise in the filter resistance was not part of the objective of this study, the frequency of flushing was not monitored. The filters were operated at a constant design filtration rate of $0.75 \mathrm{~m} / \mathrm{h}$ throughout the study period. Figure 1 shows the pilot-plant scale HRF unit used.

\section{Results and discussions}

Using Eq. (6) and the total $E$-value for the whole filter, Table 2 was generated for predicted HRF effluent $\left(C_{e}\right)$ for every

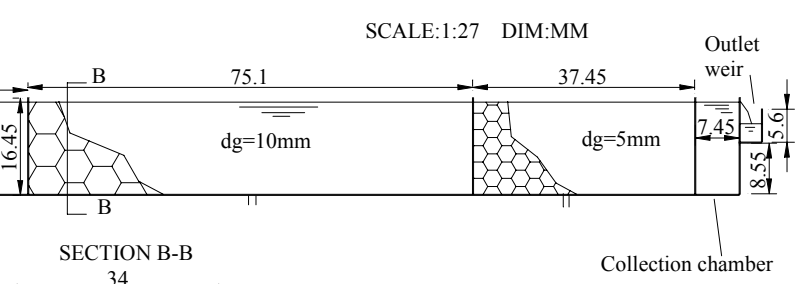

SCALE: $1: 13.5$

DIM:MM

TABLE 2

Actual field HRF outlet and predicted (Wegelin's model output) SS concentrations for all raw water SS concentrations

\begin{tabular}{|c|c|c|c|c|c|}
\hline \multirow{2}{*}{$\begin{array}{c}\text { Run } \\
\text { time } \\
\text { (days) }\end{array}$} & \multirow{2}{*}{$\begin{array}{c}C_{0} \\
(\mathrm{mg} / \mathrm{\ell})\end{array}$} & \multicolumn{4}{|c|}{$C_{e}(\mathrm{mg} / \mathrm{l})$} \\
\hline & & Predicted & HRFB & HRFC & HRFG \\
\hline 3 & 10.50 & 0.29 & 4.39 & 4.09 & 4.26 \\
\hline 5 & 9.20 & 0.26 & 3.58 & 3.31 & 3.80 \\
\hline 7 & 13.20 & 0.37 & 4.88 & 5.02 & 4.26 \\
\hline 10 & 14.60 & 0.41 & 3.96 & 4.62 & 3.24 \\
\hline 12 & 11.50 & 0.32 & 2.65 & 3.65 & 2.86 \\
\hline 14 & 9.50 & 0.27 & 2.58 & 3.04 & 2.91 \\
\hline 17 & 16.80 & 0.47 & 3.60 & 3.16 & 2.34 \\
\hline 19 & 23.20 & 0.65 & 3.34 & 1.98 & 3.10 \\
\hline 21 & 15.70 & 0.44 & 3.18 & 2.20 & 2.32 \\
\hline 24 & 13.62 & 0.38 & 2.36 & 1.89 & 3.50 \\
\hline 26 & 10.89 & 0.30 & 2.18 & 2.56 & 3.15 \\
\hline 28 & 14.60 & 0.41 & 3.50 & 3.80 & 3.90 \\
\hline 31 & 18.60 & 0.52 & 3.98 & 3.18 & 3.00 \\
\hline 33 & 19.60 & 0.55 & 2.40 & 2.60 & 2.85 \\
\hline 35 & 9.80 & 0.27 & 1.90 & 3.21 & 3.00 \\
\hline 38 & 18.40 & 0.52 & 3.20 & 2.40 & 2.00 \\
\hline 40 & 19.00 & 0.53 & 3.60 & 2.10 & 6.00 \\
\hline 42 & 12.30 & 0.34 & 2.60 & 3.00 & 3.30 \\
\hline 46 & 22.50 & 0.63 & 3.80 & 3.50 & 2.80 \\
\hline 52 & 16.80 & 0.47 & 4.80 & 4.00 & 4.80 \\
\hline 53 & 31.72 & 0.89 & 3.20 & 3.07 & 4.00 \\
\hline 54 & 24.40 & 0.68 & 3.20 & 2.80 & 3.60 \\
\hline 55 & 30.10 & 0.84 & 3.40 & 2.00 & 2.60 \\
\hline 60 & 48.80 & 1.37 & 3.40 & 2.40 & 3.80 \\
\hline 61 & 42.40 & 1.19 & 5.60 & 4.40 & 5.20 \\
\hline 62 & 48.00 & 1.34 & 6.80 & 7.60 & 4.8 \\
\hline 66 & 58.60 & 1.64 & 1.80 & 3.21 & 4.00 \\
\hline 68 & 84.00 & 2.35 & 0.80 & 2.60 & 3.20 \\
\hline 70 & 72.00 & 2.02 & 2.00 & 3.60 & 2.40 \\
\hline 73 & 116.00 & 3.25 & 3.00 & 5.20 & 4.00 \\
\hline 75 & 67.50 & 1.89 & 4.80 & 4.80 & 7.00 \\
\hline 76 & 99.33 & 2.78 & 3.50 & 3.33 & 3.43 \\
\hline 80 & 49.00 & 1.37 & 2.90 & 3.00 & 3.45 \\
\hline 81 & 49.32 & 1.38 & 1.33 & 3.62 & 4.26 \\
\hline 82 & 33.60 & 0.94 & 2.00 & 1.94 & 4.36 \\
\hline \multicolumn{2}{|c|}{$\begin{array}{l}\text { Standard } \\
\text { deviation }\end{array}$} & \pm 0.763 & \pm 1.207 & \pm 1.158 & \pm 1.047 \\
\hline $\begin{array}{l}\text { Key: } \\
\text { SS: Sus } \\
C_{0}: \text { Raw } \\
C_{e}: \text { HRI } \\
\text { HRFB: } \\
\text { HRFC: } \\
\text { HRFG: }\end{array}$ & $\begin{array}{l}\text { aded solid } \\
\text { ater SS (i } \\
\text { utlet SS } \\
\text { RF with b } \\
\text { RF with c } \\
\text { RF with g }\end{array}$ & $\begin{array}{l}\text { Concentrati } \\
\text { HRF inlet } \\
\text { ken burnt br } \\
\text { rcoal maize } \\
\text { vel as filter }\end{array}$ & $\begin{array}{l}\text { ks as filt } \\
\text { bs as filt } \\
\text { dium }\end{array}$ & $\begin{array}{l}\text { medium } \\
\text { medium }\end{array}$ & \\
\hline
\end{tabular}

recorded raw water SS $\left(C_{0}\right)$, where $C_{e}$ represents the Wegelin's model output. Using Table 2, a graph was plotted (Fig. 2) to 


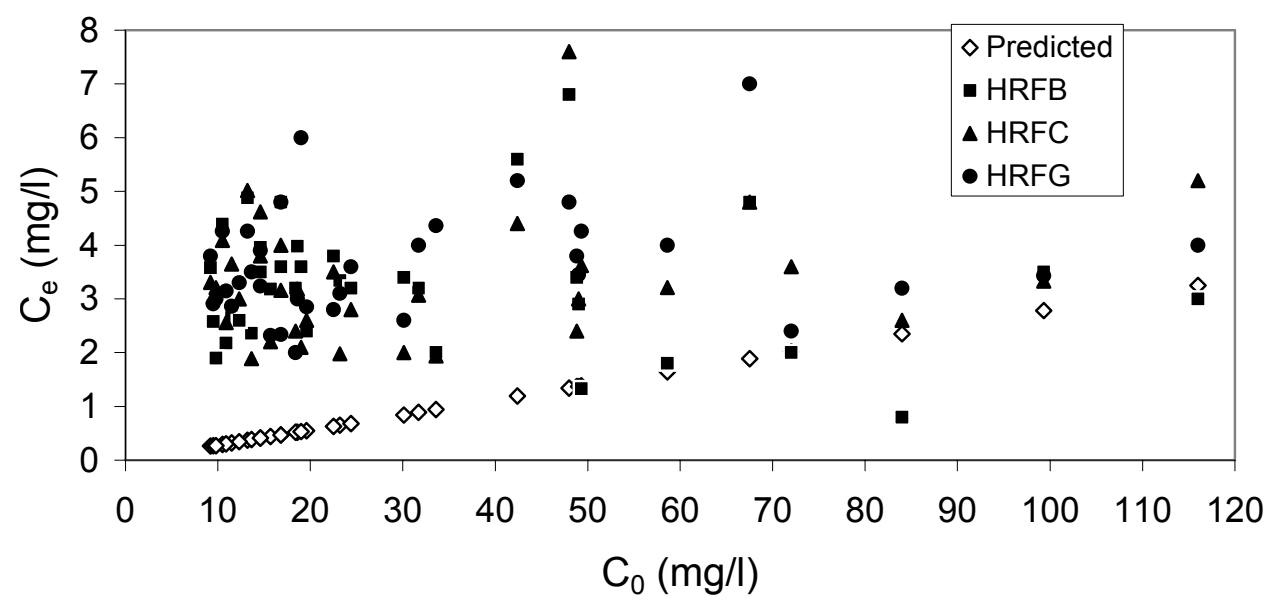

Figure 2

Comparison of observed Ce versus predicted $\mathrm{Ce}$ for the HRF units

show a graphical comparison between the effluent SS of pilot plant HRFs and the model expected output for each recorded raw water SS concentration.

\section{Validating Wegelin's theory}

From Table 2, it can be observed that the HRF $C_{e}$ (Columns 4, $5,6)$ met the required levels for safe and longer SSF operation $(<5 \mathrm{mg} / \ell)$ in most instances even though none of the filters performed close to the predicted $C_{e}$ according to the Wegelin's model (Column 3). This disparity between the predicted $C_{e}$ and observed $C_{e}$ for the three HRFs is clearly observed in Fig. 2. Given that the filter operating conditions (except for the filter material) were the same in terms of the filtration rates, material grading, filter sizes and the same raw water source with its particular suspension characteristics, one would have foreseen a possible direct fit of the observed data to the predicted values. However, as expected, the " $1 / 3-2 / 3$ " filter theory could not produce an exact fit as is the case with most filtration theories. This is possibly because, whether simple or complex, the filtration theories provide an interpretation of observed facts concerning the particular filters and suspensions studied by each investigator. These facts are thus not wholly representative of different conditions of filter type and suspension. This observation confirms the findings of other researchers on the applicability of the various filtration theories. Precedence in this field as cited by Ives (1983) was set by among others O'Melia and Werner (1967) who compared several filtration theories by evaluating the relationships which they predict between the filter coefficient $(\lambda)$ and the variable sand size $\left(\mathrm{d}_{\mathrm{s}}\right)$, filtration velocity (v) and water viscosity $(\mu)$. The results were markedly different.

\section{Performance of HRFs}

In terms of the general performance of the HRFs, the following observations were made based on Table 3 .

From Table 3 it was observed that none of the HRFs produced the exact prediction in terms of the per cent SS reduction in the raw water. However, the HRFs produced better results during the high peak periods with HRFB, HRFC, and HRFG being off prediction by $3 \%, 4 \%$ and $5 \%$ respectively. This observation could be attributed to the fact that during the design of HRFs, the resulting parameters in terms of the filter length and filtration rates were chosen based on extreme conditions. In this study, based on the preliminary tests, a value of $200 \mathrm{mg} / \ell \mathrm{SS}$ was used. This categorised the condition as

\begin{tabular}{|c|c|c|c|c|}
\hline \multicolumn{5}{|c|}{$\begin{array}{c}\text { TABLE } 3 \\
\begin{array}{c}\text { Average per cent SS reduction for the three HRFs } \\
\text { in comparison to the predicted reduction }\end{array}\end{array}$} \\
\hline \multirow[b]{2}{*}{ Period } & \multicolumn{4}{|c|}{ Average SS reduction (\%) } \\
\hline & Predicted & HRFB & HRFC & HRFG \\
\hline High peak & 97 & 94 & 93 & 92 \\
\hline Low peak & 97 & 78 & 78 & 77 \\
\hline Both peaks & 97 & 84 & 84 & 82 \\
\hline Std dev & \pm 0.763 & \pm 1.207 & \pm 1.158 & \pm 1.047 \\
\hline
\end{tabular}

medium in accordance with the Wegelin criteria. Hence, in the high peak period, the SS, even though not to the design level, could have been high enough to promote sedimentation and other filtration processes such as adsorption to register high removal efficiency.

In the low-peak period, a lower reduction percentage for all the filters was recorded with both HRFB and HRFC being off prediction by $19 \%$ and HRFG by $20 \%$. This observation could be attributed to the fact that low SS in the dry season could have possibly reduced the sedimentation process due to a possible increase in the colloidal stability and hence less particle interaction. Consequently, the concentration of settleable particles to be removed in the filter was reduced. This observation is in line with similar studies by Wegelin and other researchers in this field. In such similar studies, it has been shown that stable suspensions rich in colloidal matter are difficult to treat by roughing filters. The addition of coagulants is usually required to enhance the filter performance. The poor performance of HRF in treating stable suspensions rich in colloidal matter could also be attributed to the fact that the dominant removal mechanism in such filters is sedimentation (settlement) with the filter material acting as miniature sedimentation tanks (Boller, 1993; Wegelin, 1996).

In terms of individual performances, it was observed that in general both HRFB and HRFC performed better than HRFG. Both HRFB and HRFC were off prediction by $13 \%$ compared to $15 \%$ for HRFG. This observation could have resulted from the reason that both charcoal maize cobs and broken burnt brick have a slightly higher specific surface area and porosity respectively to enhance the sedimentation and other filtration processes compared to gravel. However, in terms of consistency in performance, HRFG was the most consistent followed by HRFC and lastly by HRFB. This was evident in the values of standard deviation of the respective $C_{e}$ where HRFG posted a standard deviation of \pm 1.047 , HRFC \pm 1.158 , and HRFB \pm 1.207 during the study period. The 
differences observed in the performance among the three HRF materials are minimal.

\section{Conclusions and recommendations}

It was observed that the performance of the HRFs did not conform to the prediction based on the " $1 / 3-2 / 3$ " filtration theory. Hence it is concluded that application of these criteria in designing HRFs for treating raw water different in characteristics from those used in developing the criteria, fails to replicate the expected results not only for the gravel medium (the medium used in developing the criteria) but also for other possible alternative filter media (in this case, charcoal maize cobs and broken burnt bricks). This proved the difficulties and the possible errors one is bound to encounter when using wholly a filter theory in design of the respective filter components without prior and thorough testing to validate the theory and design.

Given the disparity observed in all the materials used in terms of fitting the predicted value, it is recommended that the " $1 / 3-2 / 3$ " filtration theory-based design be used as a guideline in developing the actual field parameters of the filter coefficient $\lambda$ for a given material considering a length-by-length analysis for each compartment making up the full filter length/depth. Care should also be taken to consider the chemical analyses to determine the possible changes occurring in raw water quality as a result of the different media in use and its effects on the removal of SS. A particle size analysis of the SS in the raw water, length-by-length outlets (for each compartment) and final filter effluent could also be important in the possible determination of $\lambda$ for different flow velocities. This exercise would also aid in the further understanding of particle removal trends and check for possible discrete or flocculent settling in the system.

Due to the financial and time constraints, the durability test of the alternative filter material (charcoal maize cobs and broken burnt bricks) was not prioritised to be within the scope of this study. However, within the operating ranges and the study period, the media remained stable. It is recommended that further studies be carried out to investigate the longevity, stability and possible rejuvenation of the material especially the charcoal maize cobs given that they are agricultural by-products stabilised via carbonation.

\section{Acknowledgements}

The authors would like to thank Moi University and the Netherlands Government through the Joint Financing Programme in Higher Education - Water Resources Engineering (WRE) Project for offering the principal author the scholarship and project funds that enabled this study to be undertaken.

\section{References}

BOLLER M (1993) Filter mechanisms in roughing filters $J$. Water SRT - AQUA 42 174-185.

CLARKE BA, JONES CJ, CROMPTON JL, DOREA CC and BERTRAND S (2004) Multi-stage filtration for developing world surface water treatment. Water Manage. 157 (3) 143-149.

JAYALATH JMJC and PADMASIRI JP (1996) Gravity roughing filter for pretreatment. Proc. 22 nd WEDC Conf. on Reaching the Unreached: Challenges for the 21 ${ }^{\text {st }}$ Century. New Delhi, India 271272.

MESFIN SHENKUT (1999) Multistage filtration in water. Proc. $25^{\text {th }}$ WEDC Conf. on Integrated Development for Water Supply and Sanitation. Addis Ababa, Ethiopia. 298-301.

MICHELE C and JOHANNES H (2004) Filter media expansion during backwash: The effect of biological activity. Water SA 30 (5) (Special edition) 599-603.

OCHIENG GM, OTIENO FAO, OGADA TPM, SHITOTE SM and MENZWA DM (2004) Performance of multistage filtration using different filter media against conventional water treatment systems. Water SA 30 (3) 361-367.

STANDARD METHODS (1995) Standard Methods for the examination of Water and Wastewater (19 ${ }^{\text {th }}$ edn.) Andrew DE, Lenore SC and Arnold EG (eds.) American Public Health Association/American Water Works Association/Water Environment Federation, Washington DC, USA.

TORABIAN A and FAZELI M (2004) A study on the efficiency of horizontal flow roughing filtration in organic materials removal from water using powdered activated carbon. Int. J. Environ. Studies $\mathbf{6 0}$ (1) 59-66.

WEGELIN M (1986) Horizontal Flow Roughing Filtration: A Design, Construction, and Operation Manual. IRCWD Report No. 06/86, The Hague, The Netherlands.

WEGELIN M (1996) Surface Water Treatment by Roughing Filters: A Design, Construction and Operation Manual. SANDEC Report No. 2/96, Swiss Centre for Development Cooperation in Technology and Management (SKAT), CH - 9000 St. Gallen, Switzerland.

WORLD HEALTH ORGANIZATION (2004) Water Treatment and Pathogen Control: Process Efficiency in Achieving Safe Drinking Water. Mark W LeChavallier and Kwok-Keung AU (eds.) IWA, London, UK. 